\title{
South African university student knowledge of eye protection against sunlight
}

\author{
Oduntan OA ${ }^{\dagger}$, Carlson $A^{*}$, Clarke-Farr P** and Hansraj $\mathbf{R}^{\S}$
}

$\dagger$, School of Physiotherapy, Sport Science and Optometry, University of KwaZulu Natal, P Bag X54001, Durban, 4000 South Africa

* Department of Optometry, University of Johannesburg, PO Box 524, Auckland Park, 2000 South Africa

** Department of Ophthalmic Sciences, Faculty of Health and Wellness Sciences, Cape Peninsula University of Technology, PO Box 652 Cape Town, 8000 South Africa

$\dagger<$ oduntanoa@ukzn.ac.za>

Received 14 November 2008; revised version accepted 4 March 2009

\section{Abstract}

Exposure to sunlight has been associated with several ocular conditions such as cataract, age-related macular degeneration, and conjunctival neoplasm. Knowledge of protective modalities and good behavioural practice involving eye protection is essential to prevent adverse effects of sunlight. The purpose of this study was to establish knowledge amongst randomly selected university students in South Africa, of prevention modalities against the adverse effects of sunlight. A questionnaire relating to the knowledge of preventive modalities was completed by randomly selected students from four universities selected by convenience sampling. Questionnaires completed by one thousand, eight hundred and thirty two $(N=1832)$ subjects were analysed with descriptive statistics using Stata version 10. The participants' ages ranged from 17 to 55 years $($ mean $=21.03 \pm 3.4$ years $)$. They included $43.7 \%$ males and $56.3 \%$ females. They were $68.3 \%$ Blacks, $20.0 \%$ Whites, 3.4\% Indians and $7.4 \%$ Coloureds. Many (82.3\%) of them knew that excessive exposure to sunlight can adversely affect the eyes. Only $28.5 \%$ reported that they often wore sunglasses outdoors. Only $38.5 \%$ of the partici- pants knew that not all spectacles or contact lenses could protect eyes from ultraviolet radiation. However, many, $87.7 \%$ and $69.5 \%$ respectively knew that sunglasses and spectacles could be specifically designed to block UVR from entering the eye. Just over half $(52.7 \%)$ knew that contact lenses can be specifically designed to block the UVR. Many, $(68.4 \%)$ agreed that wearing hats with brims could protect the eyes against harmful radiation from the sun and the majority, $95.8 \%$ agreed that there was a need for awareness campaigns about the effects of the sun on the eye and against excessive exposure. Female respondents had more knowledge of preventive modalities than the males. Knowledge of preventive modalities among the respondents varied significantly with the type of questions and was poor for certain questions. This suggests a need for an eye protection awareness campaign amongst the general population in South Africa, about the possible adverse effects of sunlight on the eye and appropriate protective practices.

Key words: Sunlight adverse effects, ultraviolet radiation, sunglasses, tinted lenses, tinted contact lenses.

\footnotetext{
$\uparrow \mathrm{BSc}$ (Hons)Optom PhD

* CertOptom(UDW) FBDO CAS

**NDOptDisp(SA) CertOptom(CT) MOptom PhD

$\S$ BOptom MOptom PhD
} 


\section{Introduction}

The sun provides heat, light and energy for the entire solar system ${ }^{1}$. The human body is exposed to terrestrial sunlight containing UVB (295-315 nm), UVA (315-400 nm), visible light (400-750 nm) and infra red $(750 \mathrm{~nm}$ to $1 \mathrm{~mm})$ radiations $^{2}$. The major source of ultraviolet radiation (UVR) is solar radiation, although artificial sources in the workplace can also emit this radiation ${ }^{3,4}$. Exposure to solar UVR is the major environmental factor implicated in the development of skin cancers, as well as eye damage and skin photo-ageing 5 . There is general agreement from epidemiological studies that exposure to UVR is a major cause of each of the common types of skin cancer (basal cell carcinoma, squamous cell carcinoma and melanoma $)^{6-9}$.

Ultraviolet radiation damage to the eyes is as a result of acute or cumulative (long term) exposure. The most commonly known adverse effect of solar UVR is inflammation of the cornea (photokeratitis) which is caused by UVB and usually resolves without long term consequences within 48 hours $^{2,10}$. However, extended exposure to the various components of solar UVR can result in other eye diseases such as melanoma of the uvea ${ }^{4}$ and lids ${ }^{11,12}$, cataract $^{13-15}$, age-related macular degeneration (AMD) ${ }^{16-20}$, pterygium $^{21-24}$ and conjunctival neoplasms ${ }^{25-26}$. It has also been reported that infra-red radiation can be harmful to the eye, causing damage to the cornea (photokeratitis), lens and the retina ${ }^{27}$.

Many teenagers and young adults in South Africa spend significant amounts of time outdoors especially at the beaches. Therefore, there is a need to assess their knowledge of the adverse effects of exposure to solar radiation and prevention practices. Such information is currently not available in the literature. Therefore, the aim of this study was to randomly sample university students in South Africa to establish their knowledge of protection against adverse effects of solar UV radiation. A preventative attitude and behaviour modification can greatly reduce the risk of the adverse effects of sunlight.

\section{Methods}

This is an explorative study to determine the knowledge of eye protection among selected university students in South Africa with regards to solar radiation.
A pre-coded questionnaire (Appendix 1) was used to collect data for this study. The purpose of the study and procedure were indicated on the questionnaire and the participants were informed that participation in the survey was voluntary. Research and Ethics approval for the study were obtained from the Research and Senior Degrees Committee, as well as the Ethics Committee of the University of Limpopo. Following approvals, a pilot study was conducted among 20 University of Limpopo students, after which necessary amendments were made to the questionnaire. The final questionnaire was randomly distributed to students at the University of Limpopo, University of Johannesburg, University of KwaZulu-Natal and Cape Peninsula University of Technology with the help of trained assistants. Convenience sampling was used to select the universities as these were the institutions where the different authors work. Also, convenience sampling was used to select participants. Research assistants were employed and assigned to various Faculties in the Universities to distribute the questionnaires. All registered students of the selected institutions were eligible for participation. Data from the questionnaires was analyzed using the Stata version 10 statistical programme. Descriptive statistics were used, namely frequencies, ranges, means and standard deviations and Chi squared tests were used to establish association between gender and some of the variables.

\section{Results}

A total of 1855 subjects completed the questionnaire in this study, but 23 of the completed questionnaires were rejected due to gross omission of data. The ages of the remaining 1832 respondents included in the analysis ranged from 17 to 55 years (mean = $21.03 \pm 3.4$ years). A large proportion, 1698 (92.5\%) were between the ages of 17 and 25 . The subjects included 801 (43.7\%) males and 1031 (56.3\%) females. Many, 1252 (68.3\%) were Blacks, 366 (20.0\%) were Whites, 63 (3.4\%) were Indians and 136 (7.4\%) were Coloured. Fifteen $(0.9 \%)$ did not indicate their race. The majority, 1142 (62.3\%) were from the Faculties of Science, Health Sciences and Engineering. Others were from the Faculties of Arts or Social Sciences (656, 35.8\%). Thirty-four $(1.9 \%)$ did not indicate their faculties of origin. 
Many $1495(82.3 \%)$ of the respondents knew that excessive exposure to sunlight can adversely affect the eyes. Other responses to this question are shown in Table 1. Those who knew this were $41.1 \%$ males and $58.9 \%$ female. There were more participants among the females $(86.1 \%)$ than among the males $(77.3 \%)$ who knew that excessive exposure can adversely affect the eyes $(p<0.05)$. The percentages of each gender who knew this are included in Table 2. Of the 1159 who responded to how excessive sunlight exposure can affect the eyes, $1071(92.4 \%)$ reported that it can damage the eyes, $5(0.4 \%)$ reported that it can cause blindness. Others, $83(7.2 \%)$ gave answers considered to be irrelevant. When asked how often they wore sunglasses outdoors, 515 (28.5\%) reported 'often', 593 (32.8\%) reported 'rarely', 699 (38.7\%) reported 'never'. Those who reported wearing sunglasses often were $35 \%$ male and $65 \%$ females and included more of the female $(33.0 \%)$ than males
(22.8\%). Only a minority, $777(42.4 \%)$ of the total respondents, reported currently having sunglasses. Among these, 259 (33.3\%) bought them from optometrists or opticians, $471(60.6 \%)$ bought them from shops and $47(6.1 \%)$ bought them from other sources.

A smaller proportion 649 (35.7\%) knew that ordinary spectacles or contact lenses cannot protect the eyes from UV radiation (Table 1). These included $277(42.7 \%)$ males and $372(57.3 \%)$ female respondents and there were more females than males who knew this $(p<0.05$, see Table 2$)$. Eight hundred and six (44.6\%) knew that not all colours of tint can block out UV radiation. These respondents were 333 (41.3\%) females and 473 (58.7\%) females. The proportions among each gender who gave this response are shown in Table 2. Again, more respondents among the females gave correct answers than males but the difference was not significant $(p>0.05)$.

Table 1: The number and percentages (in parentheses) of all participants who responded to the questions are indicated in the table. The number and percentages of participants who got the answers correct varies significantly.

\begin{tabular}{|l|c|c|c|}
\hline \multicolumn{1}{|c|}{ Questions } & Yes & No & No idea \\
\hline $\begin{array}{l}\text { Can excessive exposure to sunlight affect } \\
\text { your eyes? }\end{array}$ & $1495(82.2 \%)$ & $152(8.4)$ & $170(9.4)$ \\
\hline $\begin{array}{l}\text { Can ordinary spectacles or contact lenses } \\
\text { protect your eyes from UV radiation? }\end{array}$ & $699(38.5)$ & $649(35.7)$ & $468(25.8)$ \\
\hline $\begin{array}{l}\text { Do all colours of tint block out UV radia- } \\
\text { tion? }\end{array}$ & $392(21.7)$ & $806(44.6)$ & $610(33.7)$ \\
\hline $\begin{array}{l}\text { Can wearing hats with brims protect your } \\
\text { eyes against harmful radiation from the sun? }\end{array}$ & $1237(68.4)$ & $332(18.4)$ & $240(13.2)$ \\
\hline
\end{tabular}

Table 2: Intra-gender (within gender) responses who responded to the questions as stated. A greater percentage of females $(86.1 \%)$ than males $(77.3 \%)$ knew that excessive sunlight can adversely affect the eyes. Higher percentages of the females knew the correct answer to all the questions included in the table.

\begin{tabular}{|l|c|c|c|c|c|c|}
\hline \multicolumn{1}{|c|}{ Questions } & \multicolumn{3}{c|}{ Males } & \multicolumn{3}{c|}{ Females } \\
\cline { 2 - 7 } & Yes & No & No Idea & Yes & No & No Idea \\
\hline $\begin{array}{l}\text { Can excessive exposure to sunlight } \\
\text { affect your eyes? }\end{array}$ & 77.3 & 11.0 & 11.7 & 86.1 & 6.4 & 7.5 \\
\hline $\begin{array}{l}\text { Can ordinary spectacles or contact lenses } \\
\text { protect your eyes from UV radiation? }\end{array}$ & 38.6 & 34.8 & 26.5 & 37.4 & 36.4 & 25.2 \\
\hline Do all colours of tint block out UV radiation? & 22.3 & 41.3 & 35.6 & 21.2 & 46.5 & 32.3 \\
\hline $\begin{array}{l}\text { Can wearing hats with brims protect your } \\
\text { eyes against harmful radiation from the sun? }\end{array}$ & 67.5 & 18.4 & 14.2 & 69.1 & 18.4 & 12.6 \\
\hline
\end{tabular}


When asked whether sunglasses can be specifically designed to block the UVR from entering the eye, $1783(97.3 \%)$ participants responded. Many (87.7\%) agreed (Table 3). Those who agreed were 665 (42.6\%) males and 898 (57.5\%) females, whereas those who disagreed were $117(53.4 \%)$ males and $102(46.6 \%)$ females. Those who agreed were $(84.9 \%)$ of the males and $(89.8 \%)$ of the females $(p<0.05)$. When asked whether spectacles can be specifically designed to block the UVR from entering the eye, 1693 (92.4\%) of the subjects responded. Many, 69.5\% agreed (Table 3). Those who agreed (1177) were 472 (40.1\%) males and $705(60 \%)$ females, and those who disagreed were $51.9 \%$ males and $48.1 \%$ females. Those who agreed were $63.8 \%$ of the male sample and $74 \%$ of the female sample $(p<0.05)$.

Table 3: Shows the percentages of the total participants who responded to the questions as stated. Many knew that sunglasses and spectacles can be specifically designed to block UV radiation.

\begin{tabular}{|l|c|c|}
\hline \multicolumn{1}{|c|}{ Questions } & Yes & No \\
\hline $\begin{array}{l}\text { Sun glasses can be specifically designed to protect the eyes from } \\
\text { UVR? }\end{array}$ & $1563(87.66)$ & $219(12.34)$ \\
\hline $\begin{array}{l}\text { Spectacles can be specifically designed to protect the eyes from } \\
\text { UVR? }\end{array}$ & $1177(69.52)$ & $516(30.48)$ \\
\hline $\begin{array}{l}\text { Contact lenses can be specifically designed to protect the eyes } \\
\text { from UVR? }\end{array}$ & $882(53.1)$ & $779(46.9)$ \\
\hline Need for campaign about the effects of the sun on the eye? & $1725(95.83)$ & $75(4.17)$ \\
\hline
\end{tabular}

Table 4: Showing the percentages of each gender who responded to the questions indicated (intra-gender or within gender responses). More of the female respondents gave correct answers.

\begin{tabular}{|l|c|c|c|c|}
\hline \multicolumn{1}{|c|}{ Questions } & \multicolumn{2}{c|}{ Males } & \multicolumn{2}{c|}{ Females } \\
\cline { 2 - 4 } & Yes & No & Yes & No \\
\hline Can excessive exposure to sunlight affect your eyes? & 84.9 & 15.1 & 89.8 & 10.2 \\
\hline $\begin{array}{l}\text { Can ordinary spectacles or contact lenses protect your } \\
\text { eyes from UV radiation? }\end{array}$ & 63.8 & 36.2 & 73.0 & 26.0 \\
\hline Do all colours of tint block out UV radiation? & 51.0 & 49.0 & 54.1 & 45.9 \\
\hline $\begin{array}{l}\text { Can wearing hats with brims protect your eyes against } \\
\text { harmful radiation from the sun? }\end{array}$ & 94.1 & 5.9 & 97.1 & 2.9 \\
\hline
\end{tabular}

Of the 1673 who responded to whether contact lenses can be specifically designed to block UV radiation, $882(52.7 \%)$ agreed as shown in Table 3. They included $372(42.2 \%)$ males and $510(57.8 \%)$ females. There were more of the females $(54.1 \%)$ than males who responded correctly (see Table 4).

A high percentage $68.4 \%$ knew that wearing hats with brims can protect eyes from solar radiation (Table1) and included 533 (43.1\%) males and 704 $(56.9 \%)$ females. The percentages of each gender who responded correctly are shown in Table 2. Although, more of the females $(56.9 \%)$ than of the males
(43.1\%) knew that wearing hats with brims could protect the eyes against the adverse effects of the sun, the difference was not significant $(p>0.05)$. Many, $1800(98.3 \%)$ responded to whether they think that there was a need for educational programs about the effects of the sun on the eye and against excessive exposure. Of these, 1725 (95.8\%) agreed (Table 3). Of the total sample, those who agreed were 740 (42.9\%) males and $985(57.1 \%)$ females. Significantly more of the females $(97.1 \%)$ than of the males respondents $(94.1 \%)$ were in favour of the need for education $(p>$ 0.05 , Table 4). 


\section{Discussion}

Ocular health effects of exposure to sunlight are enormous and includes photokeratitis, photoconjunctivitis, climatic droplet keratopathy, pinguecula, pterygium and squamous cell carcinoma, anterior uveitis, ocular malignant melanoma and cataract (ophthalmoheliosis) $)^{8,28}$. As the sun is the most common source of UVR, individuals who are exposed to sunny environments should be counselled about proper eye protection from UVR in sunlight ${ }^{29}$. The main forms of ophthalmic UVR-protection are sunglasses, glasses and contact lenses into which UVR absorbing components have been incorporated ${ }^{30}$. One would expect the general population to know the ophthalmic devices that can effectively protect their eyes from adverse effects of the sunlight. In addition, they should be aware of the non-ophthalmic protection modalities. One way of assessing this knowledge is via a survey of this nature. The findings of the survey will dictate the need for an educational campaign on effective protection from adverse effects of the sun.

Awareness of the hazards of solar ultraviolet radiation (UVR) among the general population in Australia has increased substantially as a result of educational campaigns such as the Sun Smart run by the Australian State Cancer Councils ${ }^{31}$. They have begun to take positive steps to protect themselves against ambient solar UVR by measures which include changing their behaviour and wearing the appropriate clothing, sunglasses and sun screen when outdoors ${ }^{31}$. It is anticipated that the present study would establish, among university students in South Africa, the level of knowledge of protection methods and protection practices against solar radiation. If the knowledge is poor among the university students, then it could be argued that the same level of knowledge or an even poorer level would be expected among the general population.

Generally, the knowledge of the participants in this study varied significantly with regard to their response to various questions. While the majority $(82.3 \%)$ knew that sunlight has adverse effects on the eye, only $35.7 \%$ knew that ordinary spectacles or contact lenses cannot protect the eyes from UV radiation. While only $44.6 \%$ knew that not all colours of tints could protect the eyes, many $(68.4 \%)$ knew that wearing hats with brims can protect the eyes against the adverse effects of the sun. While the majority, just over half of the respondents knew that contact lenses can be designed for the same purpose (Table 3). Although the knowledge was generally good, the practice is not as good as only $28.5 \%$ reported wearing sunglasses often, outdoors and only $34.4 \%$ of these bought the lenses from optometrists. The majority bought them from shops. It may be difficult to establish whether those bought from the shops were able to protect the eyes or not. Therefore, the people need to be advised to purchase their sunglasses from optometrists so that they could be sure of the quality of such devices. An interesting finding was that, in more cases, females gave correct answers than males in all the questions responded to and had better protective practices. These suggest that females take better care of their eyes than men.

The study shows that there are a few people in the population with poor knowledge and poor protective practices against dangerous solar radiations which may result in a series of eye diseases such as cataract, melanoma, pterygium et cetera. The fact that many $(63.4 \%)$ of the respondents were Health and Sciencerelated students suggests that possibly, the knowledge and practices might even be worse in a general population. It is however, relevant that an overwhelming proportion $(95.8 \%)$ felt that there was a need for educational programmes about the effects of the sun on the eye and against excessive exposure. It is therefore recommended that the Departments of Health and professional associations such as the South African Optometric Association should take the lead in awareness campaigns about eye protection against the adverse effects of the sun.

Most university students are young adults who are likely to spend a lot of time outdoors for recreational purposes and also are considered to be the parents of tomorrow; hence their knowledge of eye protection against solar radiation will be valuable to themselves and their children. This study suggests that there is a need for awareness campaigns on the adverse effects of sunlight, protection practices and knowledge of protective devices. This will enhance better protection practices against sunlight. In conclusion, this study shows that the knowledge of protection against the detrimental effects of UVR is not adequate. There is therefore a need for active awareness campaigns in South Africa. 


\section{Acknowledgement}

The authors would like to acknowledge the assistance of Mrs Fikile Nkwanyana in the data analysis. We are grateful to all the participants in this study and the South African Universities that provided the materials used for the study.

\section{References}

1. Pitts DG. The electromagnetic spectrum. In: Pitts DG and Kleinstein RN, eds. Environmental vision: Interaction of the eye, vision and the environment. Butterworth-Heinemann: Boston, 1993 p100.

2. Young AR. Acute effects of ultraviolet radiation on human eyes and skin. Progr Biophys Mol Biol 200692 80-85.

3. Thieden E, Philipsen PA, Heydenreich J, Wulf HC. Ultraviolet radiation exposure related to age, sex, occupation, and sun behaviour based on time-stamped personal dosimetry readings. Arch Dermatol 2004140 197-203.

4. Shah CP, Weis E, Lajous M, Shields JA, Shields CL. Intermittent and chronic ultraviolet light exposure and uveal melanoma: a meta-analysis. Ophthalmol 2005112 15991607.

5. Kimlin M, martinez N, Green AC, Whiteman DC. Anatomical distribution of solar ultraviolet exposure among cyclists. J Photochem Photobiol 200685 23-27.

6. Diffey B. Ozone depletion and skin cancers. Br Med J 1992 304 1176-1177.

7. Bulliard J-L, Hugh A. Site-specific risk of cutaneous malignant melanoma and pattern of Sun exposure in New Zealand. Intern J Cancer 200085 627-632.

8. De Gruijl FR, Longstreth J, M Norval, Cullen A P, Slaper H, Kripke M L, Takizawa Y, van der Leun J C. Health effects from stratospheric ozone depletion and interactions with climate change. Photochem Photobiol Sci 20032 16 - 28.

9. Faurschou, A, Haedersdal, M, Poulsen, T, Wulf, H C. Squamous cell carcinoma induced by ultraviolet radiation originates from cells of the hair follicle in mice. Exp Dermatol 200716 485-489.

10. Johnson GJ. The environment and the eye. Eye 200418 1235-1250.

11. Sun EC, Fears TR and Geodert JJ. Epidemiology of squamous cell conjunctival cancer. Cancer Epidemiol Biomark Prev 19976 73-77.

12. Yu GP, Hu DN, McCormick SA. Latitude and incidence of ocular melanoma. Photochem Photobiol 200682 16211626.

13. Delcourt C, Carriere I, Ponton-Sanchez A, Lacroux A, Covacho M Papoz L. Light exposure and risk of cortical nuclear and posterior subcapsular cataracts. The Pathologies Oculaires Liees a l'Age (POLA) Study. Arch Ophthalmol 2000118 385-392.

14. Neale RE, Purdie JL, Hirst LW and Green AC. Sun exposure as a risk factor for nuclear cataract. Epidemiol 200314 707-712.

15. Mafia K, Gupta R, Kirk M, Wilson L, Srivatava OP, Barnes
S. UV-A induced structural and functional changes in human lens deamindated by B-crystallin. Mol Vis 200814 234-248.

16. Cruickshanks KJ, Klein R, Klein BE and Nondahl DM. Sunlight and the 5-year incidence of early age-related maculopathy: The Beaver Dam Eye Study. Arch Ophthalmol 2001119 256-250.

17. Wang JJ, Jakobsen K, Smith W, Mitchell P. Five-year incidence of age-related maculopathy in relation to iris, skin or hair colour and skin sun sensitivity: the Blue Mountain Eye Study. Ophthalmol 200331 317-321.

18. Tomany SC, Cruickshanks KJ, Klein R. Sunlight and the 10 year incidence of age- related maculopathy: the Beaver Dam Eye Study. Arch Ophthalmol 2004122 750-757.

19. Plestina-Borjan I, Klinger-Lasic M. Lomg-term exposure to solar ultraviolet radiation as a risk factor for age-related macular degeneration. Coll Antropol 2007 (Suppl 1) 33-38.

20. Hirakawa M, Tanaka M, Tanaka Y, Okubo A, Koriyama C, Tsuji M, Akiba S, Miyamoto, K, Hillebrand G, Yamashita T, Sakamoto T. Age-related macular degeneration and sunlight exposure evaluated by objective measurement. $\mathrm{Br} J \mathrm{Oph}$ thalmol 200892 630-634.

21. Di Girolamo N, Chui J, Coroneo MT. Pathogenesis of pterygia: role of cytokines, growth factors and matrix metalloproteinases. Prog Ret Eye Res 200523 195-228.

22. Paula JS, Thorn F and Cruz AA. Prevalence of pterygium and cataract in indigenous populations of the Brazilian Amazon forest. Eye 200620 533-536.

23. Ma K, Xu L, Jie Y Jonas JB. Prevalence of and factors associated with pterygium in adult Chinese: The Beijing Eye Study. Cornea $2007261184-1186$.

24. Gazzard G, Saw SM, Farook M, Koh D, Widjaja D Chia SE, Hong CY, Tan DT. Pterygium in Indonesia: prevalence, severity and risk factors. Br J Ophthalmol 200286 13411346.

25. Lee GA, Hirst LW. Ocular surface squamous neoplasia. Surv Ophthalmol 199539 429-450.

26. Basti S, Macsai MS. Ocular surface squamous neoplasia: a review. Cornea 200322 687-704.

27. Zuclich, J A, Lund J, Stuck E. Wavelength dependence of ocular damage thresholds in the near-IR to far-IR transition region: proposed revisions to maximum permissible exposures. Health Phys 200792 15-23.

28. Longstreth J, De Gruijl FR, Kripke ML, Abseck S, Arnold F, Slaper HI, Velders G, Takizawa Y, van der Leun JC. Health risks. J Photochem Photobiol 199846 20-39.

29. Sheedy JE, Eldlich RF. Ultraviolet eye radiation: The problem and solutions. J Long Term Effects Med Impl 200414 67-71.

30. Moore LA. Ocular protection from solar ultraviolet radiation (UVR) in sports: factors to consider when prescribing. S Afr Optom 200362 72-79.

31. Gies PH, Roy CR, Toomey S, McLennan A. protection against solar ultraviolet radiation. Mut Res 1998442 1522. 


\section{Appendix}

Questionnaire: Knowledge of eye protection against sunlight among university students in South Africa

Name of Institution:

Dear participant,

This survey is being conducted to establish the protective practices against the adverse effects of the sun among the University students in South Africa. The outcome of this study will assist in guiding optometrists in educating the public on protection against the adverse effects of the sun. Your input in completing this questionnaire is very valuable. Your responses will be kept strictly confidential. Your co-operation is greatly appreciated. Please, complete the questionnaire to the best of your knowledge. Tick and/ or complete the blank spaces.

1. Age ........ [ ] (Years)

2. Gender: Male $=1[$ ] female $=2$ [ ]

3. Race: Black $=1[$ ] Indian $=2$ [ ] White $=3$ [ ] Coloured $=4$ [ ] Other (Specify) =99 [ ]

4. Faculty: Sciences, Health Sciences, agric, engineering etc $=1[$ ]

Arts, law and social and management sciences etc $=2$ [ ]

5. Can excessive exposure to sunlight adversely affect your eyes?

Yes $=1[$ No $=2[$ N No idea $=3[$ ]

If your answer is 'No', go to Question 7

6. How often do you wear sunglasses when you are outdoors?

Often $=1[$ [ Rarely $=2$ [ ] Never $=3$ [ ]

If your answer is 'Rarely' or 'Never', go to Question 9

7. If you currently have sunglasses, where did get them from?

Optometrist / Optician $=1 \quad[\quad]$ Shop $=2$ [ ] other, Specify $=99$ [ ]

8. Can ordinary spectacles and contact lenses protect your eyes from UV radiation?

Yes $=1[$ No $=2$ [ ] No idea $=3$ [ ]

9. Do you know that the ophthalmic devices listed below can be specifically designed to block some UV radiation entering your eyes?

(a) Sunglasses: Yes $=1 \quad[$ No $=2[$ ]

(b) Spectacles: Yes $=1 \quad[]$ No $=2[$ ]

(c) Contact lenses: Yes $=1 \quad[\quad]$ No $=2$ [ ]

10. Do all colours of tints (shades) block out UV radiation?

Yes $=1[$ No $=2$ [ ] No idea $=3[$ [ ]

11. Can wearing of hat (with brims) protect your eyes against harmful radiations from the sun? Yes = $[$ ] No $=2[$ ] No idea $=3[$ ]

12. Do you think that there is a need for education programs about the effects of the sun on the eye and protection against excessive exposure?

Yes $=1[] \quad$ No $=2[]$

Thank you for completing this questionnaire. 